- South Korean research ship had to rescue Chinese workers - whom the Xuelong was supposed to pick up - stranded on an island in Terra Nova Bay, where they had been building the country's fifth Antarctic research station.

Other members of the Chinese Antarctic expedition squeezed in as much science as possible before departing on the Xuelong. One group installed a meteorological station about 100 kilometres from Zhongshan to collect data that will improve Antarctic weather forecasts. And the Xue Ying aircraft, China's only polar-research aeroplane, gathered geophysical observations of the ice sheet.

China is expanding its scientific activities in Antarctica, an ambition outlined in the country's five-year plan that began in 2016. This season, workers finished a second stage of construction at a research station that opened in 2014 about 500 kilometres from Zhongshan. China has also announced plans to build an airstrip on the ice near Zhongshan.

\section{WHAT LIES BENEATH}

Next year, if Talalay and his colleagues can secure funding, they plan to take their drill to the site of this future runway. They want to drill through the ice to help better monitor how ice flows in the area and where crevasses are likely to form, Talalay says. Working at the site would also allow them to take their drill to the next level of testing, because the ice there is 600-800 metres thick - substantially more than they drilled through this year.

The team hopes to eventually use the drill to penetrate more than 1 kilometre of ice to extract a rock core from one of Antarctica's biggest geological mysteries: the Gamburtsev Mountains, a range that is similar to the Alps but about which little is known because it lies so deep beneath the ice. Like ice cores, which tell the story of changing environmental conditions as the ice formed, rock cores reveal the story of a region's geology.

Antarctica's vast ice sheet covers almost the entire continent. The Gamburtsev Mountains are known to exist because they appear in radar images, but are a geological puzzle because they occur in the middle of the continent, "I'm where researchers 'I'm sure they're think there has been rightfully little tectonic activity excited to have for more than half a core in hand." billion years. Drilling directly into the Gamburtsevs would allow geologists to begin testing ideas of how the mysterious range formed.

Drilling in Antarctica is hard because of the cold temperatures and the logistical difficulties of transporting large amounts of equipment (J. Wang et al. Polar Sci. 9, 208-220; 2015). So far, scientists have recovered only a handful of rock cores from beneath the Antarctic ice sheet. These include an 8-metre-long core from the Pirrit Hills area of West Antarctica, collected by US researchers in the 2016-17 season (O. Spector et al. Cryosphere 12, 2741-2757; 2018).

Last month, a team from the University of Glasgow, UK, was hoping to collect a small sample of bedrock from the bottom of a hole drilled in West Antarctica by the British Antarctic Survey. But technical problems, including misbehaving motors, scuttled the plan, says team leader Patrick Harkness, an ice-drilling engineer at the University of Glasgow.

To retrieve their rock core, Talalay's team, led in the field by drilling engineer Zhang Nan of Jilin University, set up its drill about 12 kilometres south of Zhongshan during December and January. The group used ice-penetrating radar to locate the top of a hill buried beneath the ice, and aimed for that subglacial peak.

After drilling through the ice, the researchers lowered a rock-drilling tool into the hole and retrieved the short rock core. The dark, blocky cylinder appears to comprise a roughly fifty-fifty mix of ice and a metamorphic rock called gneiss, Talalay says.

The team's success is "a significant accomplishment”, says John Goodge, a geologist at the University of Minnesota in Duluth who is helping to develop a US drill meant to quickly bore through the Antarctic ice and reach the bedrock below. "I'm sure they are rightfully excited to have core in hand," he says.

Drilling into the Gamburtsev Mountains is a long-standing goal of the Chinese and US Antarctic research programmes, Goodge notes. Such rock samples could help to reveal how long the Antarctic ice sheet has existed above them, and whether there are any buried lakes or basins that could preserve evidence of life beneath the ice.

But getting through more than a kilometre of ice - while working in extreme cold, at high elevation, and far from an established major research base - is extremely difficult. So the Gamburtsevs may have to wait a while. "Can it be done?" Goodge asks. "I think so. But because of the many technical challenges it isn't going to happen soon." - of respondents who had been harassed had not reported the incident to their employer. Nearly one-third of respondents also said their workplace's policies on preventing sexual harassment were ineffective. And 33\% thought procedures for addressing reported incidences of sexual misconduct were inadequate (see 'Sexual harassment in science').

Policies on how to prevent sexual harassment and bullying, and how to handle incidents after they occur, have been available for several years, says Wafa El-Adhami, executive director of the Science in Australia Gender Equity (SAGE) initiative in Canberra. But the results suggest that there is poor awareness of these policies, or they aren't being implemented effectively, El-Adhami says. She advocates greater accountability for organizations, to ensure that policies work. "You lift the awareness as you make managers and senior leaders accountable," she says.

The survey was carried out over two weeks in late January and early February by the STA, which represents about 70,000 scientists. Nearly $60 \%$ of respondents worked in academia; the rest worked in the government (25\%), the private sector (12\%) or non-profit 


\section{SEXUAL HARASSMENT IN SCIENCE}

A survey of 296 Australian science professionals found that one woman in two has been sexually harassed at work. More than one-third of female respondents thought their workplace's sexual-harassment policies were inadequate.

Have you experienced sexual harassment in the workplace?

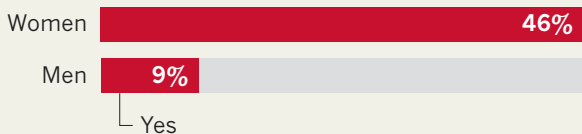
No Preferred not to say

My workplace's policies and procedures are effective at preventing sexual harassment in the workplace.

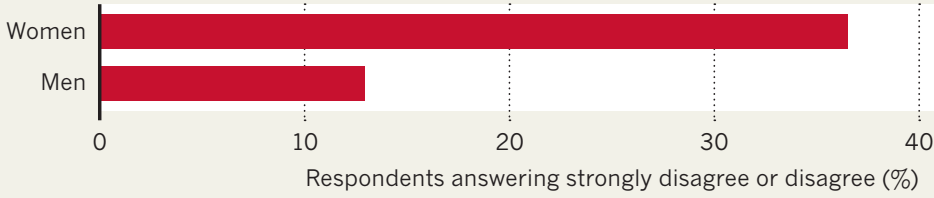

My workplace's policies and procedures are adequate at addressing incidences of sexual harassment.

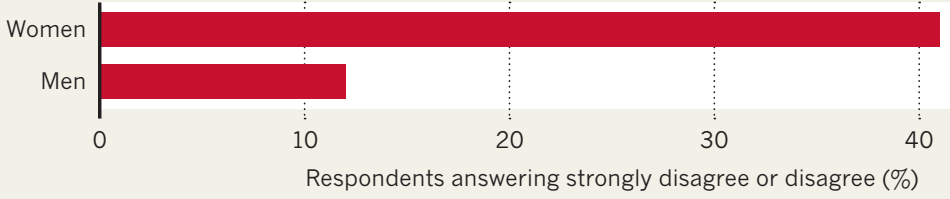

organizations (5\%). The results form part of the STA's submission to a national inquiry into sexual harassment in workplaces, run by the Australian Human Rights Commission.

Female respondents from sexual and gender minority groups (LGBT+) were at the highest risk: 13 out of the 20 women in this group reported experiencing sexual harassment at work. One of the seven male respondents in this group also reported being harassed.

LGBT+ people had even less confidence in their workplace's policies for addressing or preventing sexual harassment than did heterosexual and cisgender respondents. They also felt less safe from reprisals, such as being ridiculed, demoted or forced to resign.

Anna Bull, a sociologist at the University of Portsmouth, UK, and co-founder of the 1752 Group - which addresses the issue of sexual misconduct in higher education - says the results echo the UK experience. "The patterns - particularly LGBTQ people feeling less safe in the workplace, feeling the policies are less adequate, and of course women experiencing high levels of sexual harassment and feeling less protected - these are all very, very familiar findings."

Although the survey numbers were small, and the voluntary nature of the study meant that the sample was self-selecting, Bull says larger studies of sexual-harassment prevalence in higher education have also shown it is a significant problem.

Emma Johnston, president of the STA, described the findings as disturbing, and a "wicked problem". But she says the survey is a step forward in understanding the problem and the urgent need to act.

The survey found that sexual harassment was less common in workplaces with greater gender balance. "That's a very strong, positive message," Johnston says, because it shows that increasing diversity has multiple benefits. Nearly all respondents agreed that addressing sexual harassment in the workplace was important in achieving gender equity in science, technology, engineering and mathematics.

In its report, the STA highlighted the need for scientific workplaces to run accredited training in dealing with sexual harassment. It also pointed out the need for greater awareness of reporting procedures: almost one-third of respondents did not know how to report an incident of sexual harassment at their work. And the report included recommendations such as making it mandatory for employers to report incidents of sexual harassment to national research funding bodies, and stripping funding and professional honours from people found to have committed harassment.

Bull commends the STA for recommending significant punishments for those found to have committed misconduct.

\section{Huge US university cancels subscription with Elsevier}

\section{University of California and publishing giant fail to strike open-access deal.}

\section{BY NISHA GAIND}

$\mathrm{T}$ he University of California - the United States's largest public university system - has cancelled its subscription with Dutch publishing giant Elsevier, after months of negotiations over a proposed deal that would have allowed university researchers to publish in Elsevier journals under open-access terms.

The move is the latest in an escalating global row between scholarly publishers and academic institutions, which are pushing to make more of the scientific literature freely available and say that the costs of publishers' subscriptions are becoming unreasonably expensive.

The University of California (UC) is the first US institution to have completely cancelled its subscription with Elsevier because of such negotiations.

"UC will embolden other institutions to take a hard line," says Joseph Esposito, a senior partner at publishing consultancy Clarke \& Esposito in Washington DC. "Some will be willing to walk away from deals." Esposito argues that pirate-paper site Sci-Hub has undermined the ability of some publishing firms to continue operating as they have before.

UC had been seeking to strike a 'readand-publish' deal that would have allowed its researchers to read papers from the publisher, as well as to publish in Elsevier journals under open-access terms. Conventional licensing deals cover only the cost of accessing paywalled articles.

But the university - which publishes nearly $10 \%$ of US research papers - said on 